\section{$\underset{\substack{\text { hommes } \\ \text { \& migrations }}}{ }$}

\section{Hommes \& migrations}

Revue française de référence sur les dynamiques

migratoires

\section{$1308 \mid 2014$}

Les Paris des migrants

\title{
Yannick Torlini, Nous avons marché
}

Paris, Al Dente, 2014, $15 €$.

\section{Mustapha Harzoune}

\section{Q OpenEdition \\ 1 Journals}

\section{Édition électronique}

URL : http://journals.openedition.org/hommesmigrations/3054

DOI : 10.4000/hommesmigrations.3054

ISSN : 2262-3353

Éditeur

Musée national de l'histoire de l'immigration

\section{Édition imprimée}

Date de publication : 1 octobre 2014

Pagination : 199-200

ISBN : 978-2-919040-29-2

ISSN : $1142-852 X$

\section{Référence électronique}

Mustapha Harzoune, «Yannick Torlini, Nous avons marché », Hommes \& migrations [En ligne], 1308|

2014, mis en ligne le 10 juillet 2015, consulté le 24 septembre 2020. URL : http://

journals.openedition.org/hommesmigrations/3054; DOI : https://doi.org/10.4000/

hommesmigrations.3054

Ce document a été généré automatiquement le 24 septembre 2020.

Tous droits réservés 


\title{
Yannick Torlini, Nous avons marché
}

\author{
Paris, Al Dente, 2014, $15 €$.
}

Mustapha Harzoune

\section{RÉFÉRENCE}

Yannick Torlini, Nous avons marché, Paris, Al Dente, 2014, 148 pages.

"Sur la fine limite entre exister et ne pas exister sur la fine limite du sensible nous avons marché gardé l'équilibre suspendus à un vide plus grand que nous et sans vertige et sans peur sans même imaginer la chute possible et le fracas de nos carcasses en bas tout en bas du devenir nous avons marché et marché et marché encore en équilibre sur cette fine limite entre le possible et l'impossible nous avons parcouru falaise après falaise toujours attentifs à ce monde qui sous nos enjambées dépérit désespère abandonne nous avons marché toujours car nous ne savons rien faire d'autre et seulement un pas et un pas et un pas et la pierre toujours la pierre qui meurtrit la plante de nos pieds désagrège le reste de cuir de nos chaussures nous avons marché comme seuls les bons à rien savent le faire nous avons marché un pas et un pas et un pas encore nous nous sommes usés jusqu'à la corde et jusqu'au tendon mais sans réticences sans jamais jamais jamais regarder en arrière ni émettre le souhait d'être ailleurs d'être demain d'être hier nous avons marché simplement là simplement engourdis courbatus et sales aussi nous avons marché et marché et marché à pierre fendre dans les jours creux les promesses d'un matin qui n'en finit pas et la curieuse quotidienneté de la pluie sur nos visages travaillés par les ans nous avons marché et il a fait froid très souvent (...)."

2 Nous avons marché est un recueil de trois textes parmi les plus originaux par son écriture - "ses" écritures plutôt - sur la migration, la mobilité, l'exil, la fuite, l'enfermement... La citation est extraite d'une longue phrase qui court, sans ponctuation, sur une cinquantaine de pages, mue par son propre souffle, sa propre énergie. Dense et pleine, la phrase progresse, gonfle, se renforce, nourrie de scansions, de répétitions, d'émotions, d'images renouvelées, d'un horizon qui va s'élargissant. Il s'agit d'un poème, à lire et à écouter, sur la marche et la décision de partir, sur cette respiration ontologique, indispensable à l'espèce humaine majoritairement sédentaire : 
la marche, depuis les origines africaines jusqu'à Calais. La marche et la fragilité du migrant, l'instable équilibre du marcheur au-dessus du vide, la transformation des corps et des âmes...

3 Yannick Torlini poursuit la même expérimentation de la langue et de la musique des mots dans les deux autres textes du recueil, "Tenir registre" et "Tarik (manuel d'exil)". Dans ce dernier, il ajoute des illustrations et des figures quasi enfantines. Ici, la répétition est faite d'entrechoquements, de heurts. Les mots comme les phrases sont refaçonnés, désarticulés, scandés, arrêtés à l'image des corps disloqués, des langues démembrées dans et par l'exil. Les temps se télescopent, les souvenirs et les fantômes tourmentent des âmes fiévreuses. Et pourtant, "le chemin mène toujours quelque part", n'en déplaise à "ceux qui ne savent plus ce qu'est la souffrance".

4 Dans La Langue et ses monstres (P.O.L., 2014), Christian Prigent évoque la littérature comme "expérience radicale de ce qui nous parle et nous assujettit". Une expérience qui n'aurait d'intérêt "que si ses voix excentriques traversent les représentations couramment admises pour composer de nouveaux accords avec le désir des hommes, leur angoisse, leur sensation d'un monde vivant". L'écriture de Yannick Torlini n'est pas un exercice gratuit et fumeux. Elle est pour le lecteur une expérience intellectuelle et physique, émotionnelle. La poétique du langage, l'écriture indocile et perturbatrice, les assemblages, le jeu des répétitions et des scansions (r)éveillent les sensibilités, stimulent rêves et imaginaires, aident à (re)penser le monde.

\section{AUTEURS}

\section{MUSTAPHA HARZOUNE}

Journaliste 